\title{
The Measures of Vocational Education Reform in Shandong to Boost the College Entrance Examination in Spring
}

\author{
Zhang Jinzhi \\ Rizhao Polytechnic, Rizhao City, Shandong 276826, China \\ zhangjinzhi@126.com
}

Keywords: Shandong province; spring college entrance examination; vocational education.

\begin{abstract}
The college entrance examination in spring can not only relieve the pressure of students' college entrance examination, but also create favorable conditions for the all-round development of quality education. In addition, the spring entrance examination in spring can also create opportunities for college enrollment expansion. From the effect of the spring college entrance examination in recent years, the effect of the college entrance examination is very significant. As a "big province of college entrance examination" in Shandong Province, the spring college entrance examination in recent years has been continuously improved and innovating, which has provided a great help to postpone the employment pressure of the society. Therefore, the vocational education in Shandong should speed up the reform and use the spring college entrance examination in spring to speed up the pace of talent training. Based on this, this paper starts with the influence of Shandong spring college entrance examination, first analyzes the current situation of Vocational Education in Shandong Province, and then studies the measures of Shandong vocational education reform to boost the spring college entrance examination, hoping to provide some reference for related research.
\end{abstract}

\section{Introduction}

\subsection{The influence of Shandong province college entrance examination in spring}

There are many college entrance examination in Shandong province. Facing the pressure of college entrance examination, more and more students choose the spring college entrance examination to increase their chances to enter the high quality university. From the specific effect of the spring entrance examination in spring, the impact of the college entrance examination on Shandong province is mainly reflected in the following aspects:

(1) the reform of school education has been promoted. The innovation of Shandong spring university entrance examination has joined the evaluation of vocational skills, so the examination of cultural quality is only one of them. In its 750 points, professional courses account for more than 400 points, which is higher than the score of cultural courses. For many schools, their culture is in place, but the students' professional skills are almost zero. In order to alleviate this situation, many colleges and universities have begun their own reform, specially set up skills training courses, hoping to promote the all-round development of students, and enable them to achieve better results in the spring college entrance examination. To a certain extent, the spring college entrance examination helps colleges and universities to achieve all-round training for students and create more comprehensive talents. This is of great significance for improving the current higher education.

(2) students have more space to choose. There are more and more people taking part in the spring university entrance examination in Shandong Province, because many students' academic achievements are not ideal, plus the competitive pressure of summer entrance examination is bigger, so they have little chance to get quality and efficiency through the summer college entrance examination. Therefore, more people choose spring college entrance examination to create more opportunities for admission, and because the content of spring university entrance examination is more comprehensive, many students with special skills can show their abilities through the spring 
college entrance examination.

(3) the change of the enrolment system. The spring university entrance exam emphasizes the all-round inspection of students, which is in line with the trend of education development. Therefore, more and more colleges and universities have entered the ranks of college entrance examination enrollment, which has a positive impact on improving the recruitment system. For the college entrance examination, it can be divided into two aspects: recruitment examination and enrollment. The transformation of examination form is only one aspect of its reform. The corresponding enrollment system is perfect, so that we can promote the development of the whole system. It is precisely because of the more extensive attention in the spring college entrance examination, so the corresponding enrollment is also constantly improving.

\section{Present situation of Vocational Education in Shandong Province}

\subsection{Characteristics of Vocational Education in Shandong Province}

Vocational education can provide a large number of talents for the society, and different regions also have their own characteristics. Taking Shandong as an example, in its own development, the characteristics of vocational education are mainly reflected in the following points:

(1) the direction of running a school is very clear. Vocational education in Shandong province is closely related to the local situation. Because of its rich experience in long-term development, they are very clear in their own reform, and have gone out of the misunderstanding of traditional vocational education. In the training of students, we can start with the ability to adapt to the society and improve their ability to practice, so in the last few years, a large number of talents have been exported.

(2) the level of teaching is high. Vocational education in Shandong province is oriented by employment. In the process of teaching, they can serve students well, train and exercise their abilities in all aspects, so students can quickly adapt to their posts after graduation, and have been well received by all walks of life.

(3) the government has strong support. Shandong province always pays much attention to educational investment, so the government has great support for vocational education. They have their own ideas in the investment and overall management, and have trained a large number of excellent vocational education institutions. At present, a complete vocational education system has been formed in Shandong province. All vocational colleges can grow up quickly under the leadership of the government, and are committed to optimizing their teaching quality.

\subsection{Problems in Vocational Education in Shandong Province}

The economic development of Shandong province and the construction of social modernization can not be separated from outstanding talents, especially professional technicians, which are in a state of shortage at present. Therefore, higher vocational colleges take a more important role and need to further accelerate their own development. From the current actual situation, the main problems in Vocational Education in Shandong province are as follows:

(1) the overall quality of the source is not high. At present, vocational education institutions in China are in an awkward social position. Some people do not know enough about them. Therefore, most of the secondary vocational schools are students who are not motivated and have poor academic achievement. According to the actual performance of the school, the overall quality of the vocational education college students is not high, the self-control ability of the school is poor and the management is more troublesome.

(2) the position of secondary vocational colleges is not clear enough. The vocational education institutions in Shandong province are not clear about their position. They don't realize that vocational education is also an important part of education in China, but they regard it as a sideline in education. At present, there is a serious situation, that is, the inequality between vocational education and general education, and the unreasonable structure of the school results in the slow development of 
vocational education.

(3) the teachers' team can not keep up with the needs of development. The most important factor that restricts the development of Vocational Education in China is that teachers cannot keep up with demand. The qualification of some special teachers is not enough, and the overall quality of teachers needs to be improved. According to the requirements of the appointed teachers, if they are undergraduates, they need more than five years' work in related positions, while those who fail to achieve the standard need more than eight years' experience. However, many teachers do not have this qualification. In addition, most teachers do not have systematic training and do not know how to impart knowledge. In the current vocational education institutions, the theoretical education and time education can not be effectively combined, and it is difficult to provide strong guidance to the students.

(4) the teaching method is backward. The teaching method is directly related to the quality of the teaching. However, there is a problem of backward teaching methods in higher vocational colleges. The modern vocational education emphasizes the theme of the students, and the teachers only play a guiding role in it, and the general education is quite different. However, in many vocational education institutions, this problem is not recognized. Teaching mode is directly applied to colleges and universities, and many field practice teaching is not in place, which directly affects the teaching effect.

(5) the construction of the course content is not reasonable. China's vocational education has not yet got rid of the disciplinary system. Although it has undergone many reforms, it still has a heavy disciplinary pattern in the process of teaching. Vocational education emphasizes the leading position of students in the whole process of learning, and the unreasonable construction of content will directly affect the quality of teaching. The current teaching content of Shandong vocational school emphasizes the role of teachers, and the new reform is not fully adapted to the current needs, which leads to the contradiction between teaching methods and teaching objectives.

(6) lack of perfect guidance of theoretical system. At present, there are few researches on Vocational Education in Shandong Province, and the depth and breadth of research are also slightly inadequate. In specific applications, there is a lack of classification and comparison, and some basic concepts are not well understood. Therefore, in practice, the lack of theoretical guidance, can only continue to explore, there will be a variety of mistakes.

\section{Reform of Vocational Education in Shandong province promoting the measures of college entrance examination in spring}

In view of the current situation of Vocational Education in Shandong province and the spring college entrance examination, we need to take corresponding measures to carry out reform, give full play to the role of spring university entrance examination and improve the quality of vocational education. According to the above analysis, the reform of vocational education can be carried out from the following points in Shandong province.

(1) improve the training mechanism. The Vocational Colleges in Shandong province should further improve the training mechanism to meet the students' various needs. Under the opportunity of the spring university entrance examination, we can diversify the training of talents. On the one hand, we should focus on employment and carry out targeted education. On the one hand, we can also send talents to universities through the spring college entrance examination. In this way, the attraction of vocational education can be improved and the diverse social needs can be met. Of course, in the course of teaching, we should also co-ordinate the learning of knowledge and the training of skills, broaden the way of learning and improve the quality of education.

(2) to further strengthen the support of the policy. Government departments can increase economic investment, not only for the construction of school facilities, but also for the aid of poor students. The family economy of students in many vocational colleges is more difficult and needs some help from the government. In this respect, the policy must be directed and clear, the funds should be shared more reasonably, and the multiple financial organizations of the society should be joined as much as 
possible. Or through the design of scholarships to improve the enthusiasm of students learning, and the implementation of school enterprise cooperation in the form of reducing the economic pressure of students learning.

(3) improve the enrollment system of vocational colleges. For the problem of low quality of vocational college students, we can take the form of local unified management, so that students can volunteer to volunteer and distribute by government departments. If it is transferred from general education to vocational education, it is necessary for students to put forward their own application, and then transfer their school status after approval. Through the control of the enrolment system, the quality of the students can be improved to a certain extent, and then the subsequent management of the students will be convenient.

(4) to increase the autonomy of vocational schools. For the support of vocational colleges, after pointing out the direction of development, the government should decentralization of running schools. Only by giving full education independence can it exert the advantage of market adjustment. For example, the financial management and management decisions of Vocational Colleges and universities can be handled independently by vocational schools. Under the current social environment, vocational education should be closely integrated with market demand, and cultivate professionals with pertinence, so that we can fundamentally improve the employment rate of schools. Of course, the autonomy of the underside vocational colleges is also helpful for promoting the spring college entrance examination. Schools can operate autonomously, and help students enter higher education through the combination of cultural courses and skills training.

(5) the reform of the management system. The reform of management system in vocational colleges can first establish evaluation mechanism and supervision mechanism, and supervise the quality and effect of teaching, which makes it easier to find various problems in teaching. Secondly, the employment system can also be improved accordingly, led by the government, combined to personnel training and social needs of the occupation colleges, which can help college occupation obtain more sufficient funds, but also can make the training more targeted. For students' employment guidance, schools and government departments should pay enough attention to let students have certain plans for their own development, so that they can learn more directionality. Finally, it is to strengthen the construction of the teacher team, only an excellent team of teachers can bring out excellent students. At present, one of the main factors that affect the development of Vocational Education in Shandong is the contradiction of teachers' demand. Based on this, the government and schools should increase investment, hire experienced teachers, organize teachers to conduct regular studies, enhance their personal capabilities, and effectively enhance the quality of vocational education. Especially in the spring university entrance examination environment, the teacher team should be further divided into two directions, namely, vocational education and college entrance examination education. We should take a key training mode to enable students to meet their own development needs through education.

\section{Conclusion}

Vocational colleges and universities have output a large number of talents for our country, and play an important role in the social and economic development. As the "big province of college entrance examination" in China, Shandong has a large number of students participating in the college entrance examination every year, and the pressure of competition is great. Therefore, the innovation of Shandong province put forward the spring entrance examination in spring, which can effectively relieve the pressure of the college entrance examination. For vocational education, the spring college entrance examination is an opportunity, because the spring college entrance examination is not only a cultural knowledge, but also a professional skill test. This vocational education mode is very appropriate. Therefore, in the years of the implementation of the spring entrance examination in the spring, the vocational education in Shandong has made great progress. But from the current situation, occupation education in Shandong Province, there are still some problems, so this paper is analyzed, and then combined with the spring college entrance examination of the environment, discusses the 
occupation education reform measures, hoped to provide some direction for the reform of Shandong province occupation education, to cultivate more the talent for our country occupation education institutions.

\section{Acknowledgements}

Shandong Province Education Science "13th Five-Year" project "education entrance examination" special "in Shandong province college entrance examination system reform research", project number: BZK20170.

\section{References}

[1] Zhu Xin Yan, Liu Wei, Pang Ying. The reform of the undergraduate enrollment and training mode of college entrance examination in Shandong Province in spring [J]. higher agricultural education, 2017, (04): 27-30.

[2] Wu Qinjing. The reform of the Shandong vocational education examination enrolment system boosted the spring college entrance examination to achieve new breakthroughs in the [N]. joint daily, 2015-04-15 (001).

[3] Xu Jianchao. A study of vocational practical physical education program in Higher Vocational Colleges in Shandong province [D]. Liaocheng University, 2014.

[4] Li Xintong. The present situation and Development Countermeasures of secondary vocational education in Shandong province [D]. Shandong Normal University, 2011.

[5] Lu Xiangmin. Higher occupation education in Shandong province launched a major reform initiatives [N]. Chinese adult education information, 2000-11-02 (003). 